\title{
Human-mediated introduction of geoengineering earthworms in the Fennoscandian arctic
}

\author{
Adrian A. Wackett $\cdot$ Kyungsoo Yoo $\cdot$ Johan Olofsson $\cdot$ Jonatan Klaminder $\mathbb{C}$
}

Received: 5 May 2017/ Accepted: 27 November 2017/Published online: 6 December 2017

(C) The Author(s) 2017. This article is an open access publication

\begin{abstract}
It is now well established that European earthworms are re-shaping formerly glaciated forests in North America with dramatic ecological consequences. However, few have considered the potential invasiveness of this species assemblage in the European arctic. Here we argue that some earthworm species (Lumbricus rubellus, Lumbricus terrestris and Aporrectodea sp.) with great geomorphological impact (geoengineering species) are non-native and invasive in the Fennoscandian arctic birch forests, where they have been introduced by agrarian settlers and most recently through recreational fishing and gardening. Our exploratory surveys indicate no obvious historical dispersal mechanism that can explain early arrival of these earthworms into the Fennoscandian arctic: that is, these species do not appear to establish naturally along coastlines mimicking conditions following deglaciation in Fennoscandia, nor were they spread by early native (Sami) cultures. The
\end{abstract}

Electronic supplementary material The online version of this article (https://doi.org/10.1007/s10530-017-1642-7) contains supplementary material, which is available to authorized users.

A. A. Wackett · K. Yoo

Department of Soil, Water and Climate, University of Minnesota, Saint Paul, MN, USA

J. Olofsson · J. Klaminder $(\bowtie)$

Department of Ecology and Environmental Science,

Umeå University, Umeå, Sweden

e-mail: jonatan.klaminder@umu.se importance of anthropogenic sources and the invasive characteristics of L. rubellus and Aporrectodea sp. in the arctic is evident from their radiation outwards from abandoned farms and modern cabin lawns into adjacent arctic birch forests. They appear to outcompete previously established litter-dwelling earthworm species (i.e. Dendrobaena octaedra) that likely colonized the Fennoscandian landscape rapidly following deglaciation via hydrochory and/or dispersal by early Sami settlements. The high geoengineering earthworm biomasses, their recognized ecological impact in other formerly glaciated environments, and their persistence once established leads us to suggest that geoengineering earthworms may pose a potent threat to some of the most remote and protected arctic environments in northern Europe.

Keywords Earthworm invasion - Arctic . Lumbricidae $\cdot$ Land use $\cdot$ Hydrochory

\section{Introduction}

Hidden underfoot, earthworms are powerful ecosystem engineers and the best-known soil macrofauna. Earthworms are found on all continents except Antarctica, but non-native earthworm populations have drawn renewed scientific interest in recent years due to their large-scale invasive properties (Hendrix 
et al. 2008). Introductions and ecological impacts of non-native earthworms are particularly well studied in the formerly glaciated forests of North America, where it is now established that earthworms were eradicated during the last glaciation (Gates 1982), but have since been reintroduced by farming, fishing, and other human activities (Cameron et al. 2007; Eisenhauer et al. 2007). Here, invasive European earthworm species (Lumbricidae) have resulted in dramatic transformations to forest soil morphologies (Alban and Berry 1994; Hale et al. 2005), inorganic nutrient availability (Resner et al. 2015), carbon cycling (Lyttle et al. 2015), understory plant communities (Hale et al. 2006), and overall ecosystem biodiversity and functioning (Craven et al. 2016). Earthworms dwelling within the organic soil horizons and the upper few $\mathrm{cm}$ of the mineral soil (epi-endogeic, i.e. Lumbricus rubellus), or those that burrow deeply (vertically or horizontally) into mineral soil (anecic Lumbricus terrestris and endogeic Aporrectodea sp., respectively) are recognized as the main 'geoengineers' and drivers of ecosystem change (e.g. Hale et al. 2005, 2006; Resner et al. 2015). These earthworms are henceforth in the text referred to as 'geoengineering earthworms'.

In Fennoscandia, earthworms have historically not been viewed as invasive. One possible reason for this differing perspective is the five millennia longer European agrarian history, for instance in southern parts of Sweden (Skoglund et al. 2012), which with the North American examples in mind likely induced a much older migration history of geoengineering earthworms. However, the alpine region of Fennoscandia (the Scandes) represents one of the last European environments where earthworm dispersal by agrarian cultures has historically been very limited. As a result, this biome likely represents one of the last northern European landscapes where peregrine earthworm communities have yet to establish. That epiendogeic and anecic Lumbricus sp and/or endogeic Aporrectodea sp. have the capacity to establish in the arctic climate of the Scandes is evident given that $L$. rubellus has been reported in similar climates within Fennoscandia (Terhivuo 1988) and Southeast Alaska (Costello et al. 2011), while various Aporrectodea sp. have also been documented in man-made biotopes at similar latitudes in Finland and Norway (Terhivuo 1988).
In this study, we test the idea that Lumbricus and Aporrectodea sp. are non-native and invasive (i.e. occurring in abundances causing significant impact on the native environment) in the Fennoscandian arctic (Fig. 1). This overall hypothesis was tested by a series of sub-hypotheses stating that these geoengineering earthworms: (1) did not enter northern boreal and arctic ecosystems via natural dispersal with brackish waters (conditions mimicking those following deglaciation); (2) did not arrive to the Scandes with traditional Fennoscandian native (Sami) cultures-in the North American analog native agrarian populations did not involve tillage and animal husbandry in the glaciated regions (Pleasant 2011) that could have facilitated earthworm introduction; and (3) are currently spreading into Fennoscandian arctic birch forests from anthropogenic point sources such as abandoned farms, cabin yards, composts, and fishing sites.

\section{Materials and methods}

Field methods and site description

Possible historical dispersal routes for geoengineering earthworms to enter the Fennoscandian arctic (Hypotheses 1 and 2) were assessed by surveying earthworm populations in primary succession gradients largely resembling those following deglaciation of Scandinavia where water in the Baltic alternated between brackish and freshwater stages (Figs. 1, 2), as well as within ancient Sami cultural soils. Hypothesis 1 was tested using primary succession gradients forming along the shoreline of the weakly brackish Gulf of Bothnia in response to isostatic uplift rates of $\sim 0.8 \mathrm{~cm} \mathrm{yr}^{-1}$ (Fig. 2). These vegetation gradients are described in detail in Svensson and Jeglum (2003). In short, two distinct temporal vegetation zones (Alnus incana, soil age $\sim 20-50$ years; Picea abies, $>200$ years) in undisturbed forests were surveyed for earthworms presumably entering the landscape via water transport (i.e. hydrochory), even though migration from adjacent terrestrial sources cannot be fully excluded. Spatial gradients traversing the Alnus and Picea forest were divided into two types: (1) gradients $(\mathrm{N}=3)$ with no evident human sources of earthworms adjacent (referred to as 'natural'); and (2) anthropogenic gradients $(\mathrm{N}=3)$ developing adjacent 


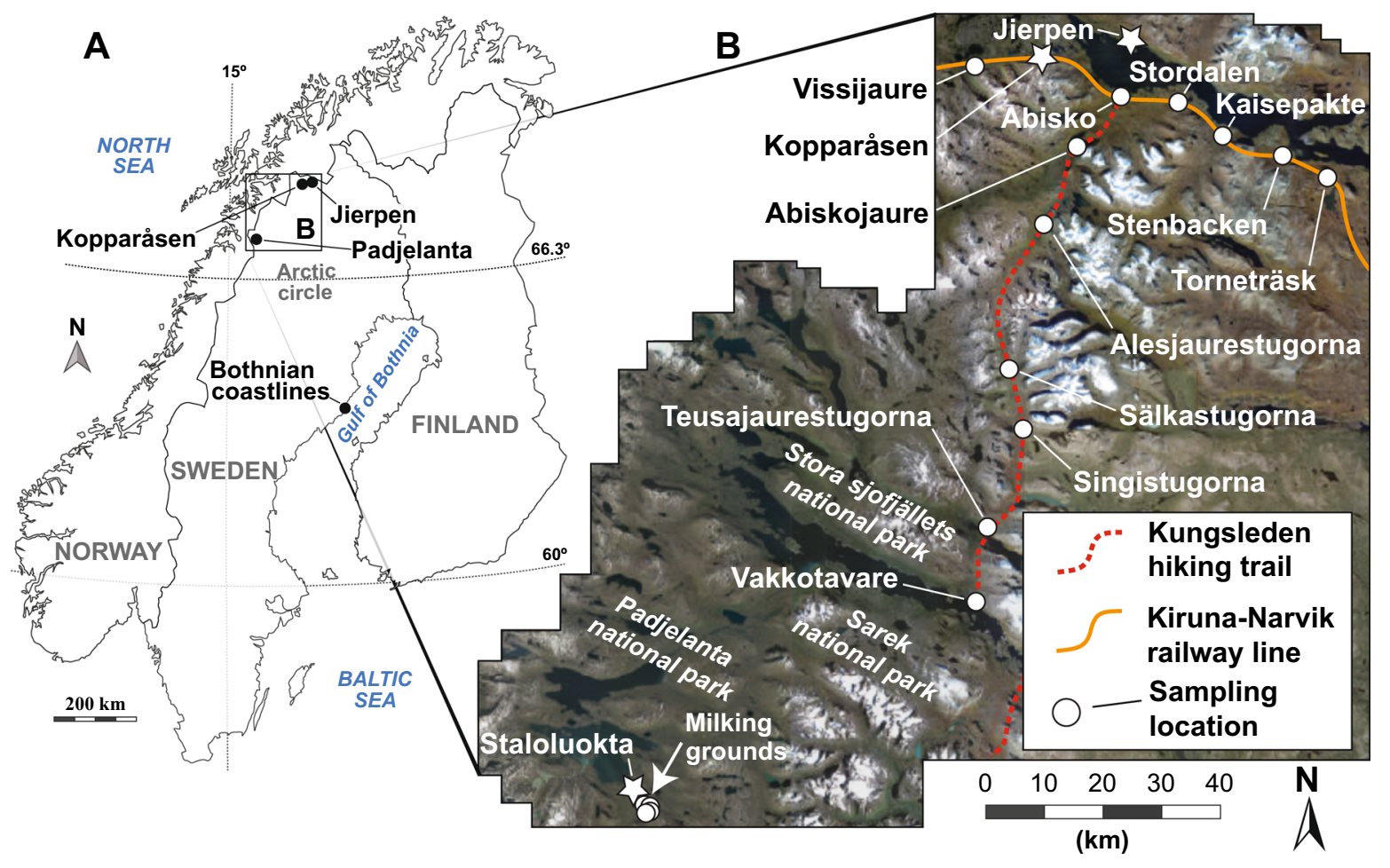

Fig. 1 a Regional map of Fennoscandia showing the main earthworm sampling locations mentioned in the text. b Aerial photo of the studied alpine biome showing locations (white circles) of the arctic earthworm survey sites. Stars symbols indicate the three gradients studied with high spatial

to human earthworm sources (cabins with flower beds, composts and lawns). In these gradients, earthworm populations were surveyed at six sites located along each gradient. Each site, located between ca 10-110 m apart, was surveyed using three replicated sub-plots $\left(0.07 \mathrm{~m}^{2}\right)$. For each sampling, the common liquid mustard extraction technique (Gunn 1992) was coupled with hand sorting of the organic soil or humus (if present) down to $15 \mathrm{~cm}$ depth. Following sampling, earthworms were identified to the species level. Measured length $(\mathrm{mm})$ was converted to ash-free dry biomass $\left(\mathrm{g} \mathrm{m}^{-2}\right)$ using the allometric equations of Hale et al. (2004) to facilitate comparison with previously published studies. This unit conversion was repeated for all survey sites (described below). In addition to the natural gradients, three gradients within the same temporal zones were traversed adjacent to known anthropogenic sources (cabins with lawns, flower beds, gardens, composts) to test whether geoengineering Lumbricus and Aporrectodea sp. could resolution (Jierpen, Kopparåsen, and Staloluokta). An arrow indicates the locations of the Sami cultural soils (reindeer milking grounds) in Padjelanta national park. Also shown are the survey points along the popular Kungsleden hiking trail and Kiruna-Narvik railway line

migrate into and survive in this environment if introduced (i.e. serving as positive controls, Fig. 2c-e).

Hypothesis 2 was tested at meadows (historical milking grounds) generated by nomadic Sami peoples within Padjelanta national park (Figs. 1, 3a, e), where nomadic Sami cultures gathered reindeer for milking for centuries (1600-1900). The more nutrient (nitrogen) rich soils in the historical milking grounds are likely to be suitable for soil-dwelling Lumbricidae; thus, if Sami cultural practices facilitated their dispersal to the landscape, these geoengineering species should be present in these areas. The unique vegetation and soils of these milking grounds are described in detail elsewhere (Egelkraut 2017). Milking ground sites $(\mathrm{N}=4)$, were surveyed for earthworms (methods as described previously) using 3-4 subplots $\left(0.07 \mathrm{~m}^{2}\right)$ per site. At each site we used a similar set of control sites $(\mathrm{N}=4)$ representing the adjacent tundra and sub-alpine birch (var. tortuosa and Betula pubescens, respectively) forest soils to allow quantification of the impact of anthropogenic disturbances on earthworm communities. 

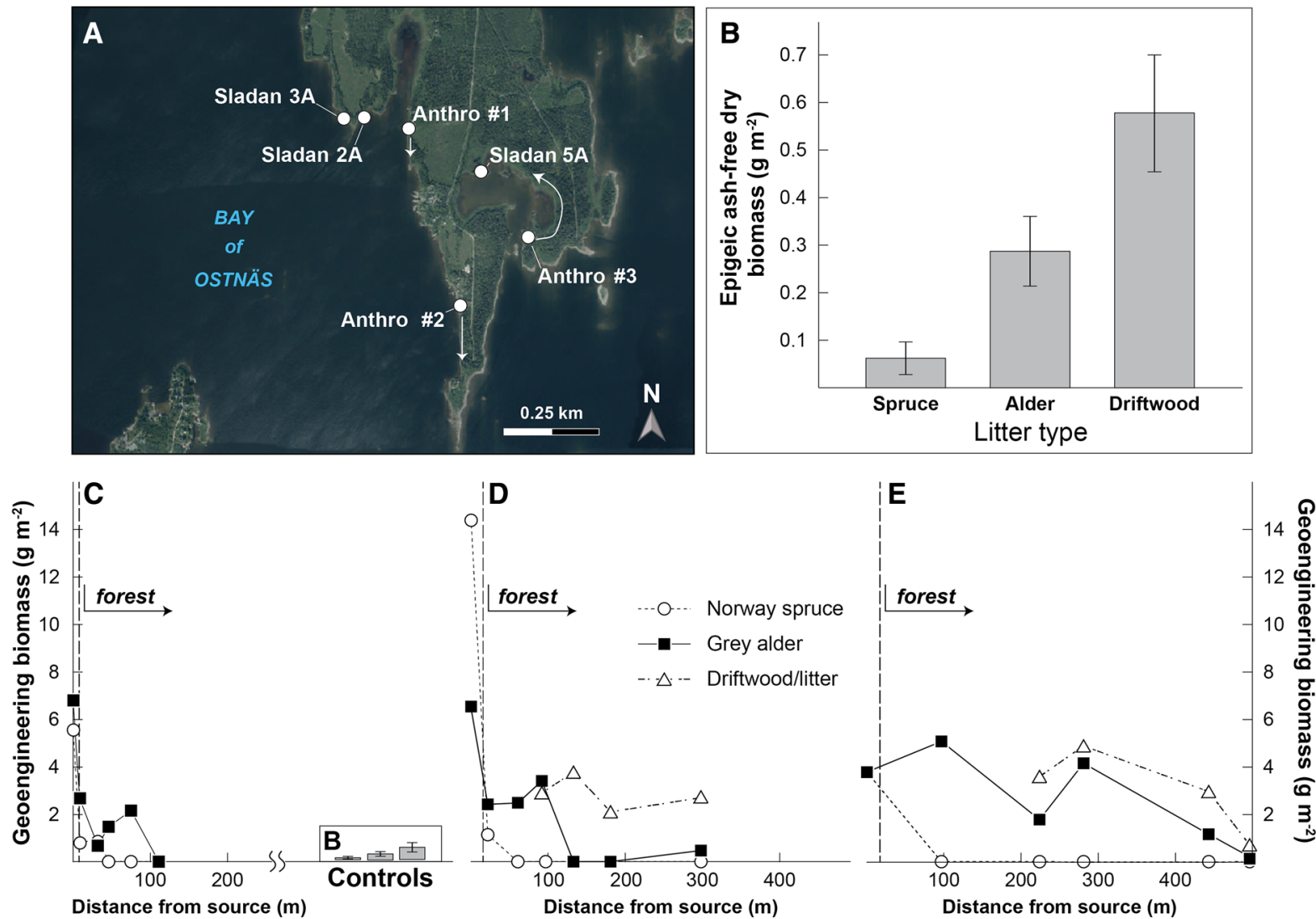

Fig. 2 a Local map of earthworm sampling gradients along rising Bothnian coastlines within the Bay of Ostnäs, including gradients not obviously disturbed by human activities (Svensson and Jeglum 2003), i.e. Sladan 2A, 3A, 5A and gradients affected by modern human disturbances (lawns and gardens, Anthro \#1-3). b Epigeic earthworm (D. octaedra and D. rubidus) biomass in distinct temporal vegetation zones at the natural gradients of Svensson and Jeglum (2003) where biomass values represent an average from individual sub-plots $(n=3)$ sampled

To test hypothesis 3 , we surveyed potential anthropogenic point sources situated in alpine environments within the Abisko area and Padjelanta national park during the summer and autumn (July through September) of 2016 and 2017. In 2016, three presumed earthworm invasion gradients extending from farms established by homesteading farmers in the late nineteenth century (Kopparåsen and Jierpen, Fig. 3b$\mathrm{d}$ respectively) as well as a modern compost (Staloloukta, Padjelanta) (Fig. 3a) were surveyed for earthworms (methods as described previously). Here, at a subjectively chosen distances from the point source, earthworm populations were surveyed using one to three replicates per distance. The gradient at within each vegetation zone at the three $(\mathrm{N}=3)$ natural gradients (i.e. total $n=9$ for each vegetation type). Note that no geoengineering species were found (geoengineering biomass $=0$ ) and thus the biomass units are different from other panels. c-e Geoengineering earthworm biomasses plotted versus distance from presumed source (lawn, garden or compost) at anthropogenic sites \#1 (c), \#2 (d) and \#3 (e). The epigeic earthworm biomasses from the natural gradients (controls) are shown as an inset in panel (c) for comparison

Jierpen was surveyed again in 2017 to cope with eventual between-year differences. During this survey, an additional control gradient was established running in parallel to the gradient intersecting with the anthropogenic source (farm), but separated from this former gradient by a stream restricting species unable to migrate via hydrochory. In these two surveys (summer 2017), we also sorted mineral soils down to a depth of $25 \mathrm{~cm}$ following the liquid mustard extraction, to cope with eventual under-selecting for endogeic (i.e. Aporrectodea) species.

Site selective surveys of earthworm species introduced from potential anthropogenic sources were also conducted (sampled as described earlier) along parts 
of the hiking trail Kungsleden (the King's trail), at abandoned farms and station homes along the KirunaNarvik railway line, and in the villages of Abisko (lawns and composts) and Staloloukta (lawns and helicopter landing ground) (Fig. 1b). The validity of hypothesis 3 was tested statistically using a regression analysis (data normal distributed) between distances from the point source versus total biomass of geoengineering (epi-endogeic, endogeic, and anecic) earthworm species for the three gradients sampled in detail (Jierpen, Kopparåsen and Staloloukta).

\section{Results and discussion}

Our earthworm surveys from primary succession gradients along the Gulf of Bothnia (Fig. 2a-e) and Sami cultural soils (milking grounds) in Padjelanta (Fig. 3a, e) revealed only the epigeic earthworm species Dendrobaena octaedra (and on some occasions Dendrodrilus rubidus in the primary succession gradients); hence, our findings support hypotheses 1 and 2. The most parsimonious explanation for the absence of Lumbricus and Aporrectodea sp. in the indigenous cultural meadows is that geoengineering species did not migrate along with the traditional Sami cultures. We cannot fully exclude the possibility that geoengineering species were once present in the Sami milking grounds, but dissipated due to natural soil acidification processes following cessation of the reindeer milking culture (late nineenth century). However, we find this scenario very unlikely as: (1) current soil $\mathrm{pH}$ around 4.3 (in $\mathrm{KCl}$ ) is above the critical $\mathrm{pH}$ of 2.5 noted for L. rubellus (Hæggström and Terhivuo 1979) and is comparable to other sites where geoengineering speices are present (Table 1); and, (2) Lumbricus sp and Aporrectodea sp. species were present only in the acidic $\left(\mathrm{pH}_{\mathrm{CaCl}_{2}}=3.3\right)$ anthropogenic primary succession gradients (Fig. 2c-e) and not in naturally formed succession soils (Fig. 2b), suggesting that the absence of geoengineering species is more likely a result of their inability to be dispersed by indigenous cultural practices rather than by soil acidity.

Findings of D. octaedra in the Padjelanta alpine soils (milking grounds and control sites) and on about $68 \%$ of the surveyed tundra and alpine birch forest sites (Table 2) is consistent with North American studies implicating this litter dwelling species as the prime colonizer of pristine soils (e.g. Gundale et al. 2005). Results from the primary succession gradients (Fig. 2b) provide a mechanistic explanation for their early arrival to the Fennoscandian landscape, as these surveys indicate that D. octaedra and D. rubidus are effectively dispersed by brackish waters (i.e. hydrochory): a mechanism previously suggested for these species (Terhivuo 1988; Terhivuo and Saura 2006). We note that the driftwood zone within these successional gradients appears to be the main habitat for these earthworms, and possibly also the main sources of cocoons. The likelihood of L. rubellus establishing via hydrochory in the post-glacial Fennoscandian landscape seems more improbable given that this species reproduces only biparentally (Muldal 1952). That is, the probability that viable L. rubellus cocoons from continental Europe traversed the brackish Baltic water and were deposited adjacent to each other on post-glacial Fennoscandian shorelines seems very low. The same holds true for Lumbricus terrestris and most of the Aporrectodea sp., although Aporrectodea rosea and Aporrectodea trapezoids are believed to be parthenogenetic (Jaenike and Selander 1979) and therefore may be exceptions. Nonetheless, based on this reasoning, and on the absence of geoengineering species in Sami cultural soils (Fig. 3e) and primary succession coastal gradients not strongly affected by human disturbance (Fig. 2b), we argue that geoengineering Lumbricus and Aporrectodea sp. are unlikely to have entered the Fennoscandian arctic biome by non-human mediated migration transport processes or with early native human cultures. Their modern presence in the arctic is likely the result of human introductions in recent centuries.

In all of the arctic gradients studied in detail, composts, fishing sites, and historic farmlands are the apparent sources of geoengineering earthworms, and their biomasses decrease significantly with increasing distance from the anthropogenic point sources into the surrounding sub-arctic birch forests (Fig. 3a-f). The invasive character of these anthropochorous geoengineering earthworms is also apparent in these gradients, as they become far more abundant than the native epigeic macrofauna, namely $D$. octaedra. In the arctic birch forest near the abandoned farms of Jierpen and Kopparåsen, we found a diverse geoeingineering earthworm species assemblage including $L$. rubellus 


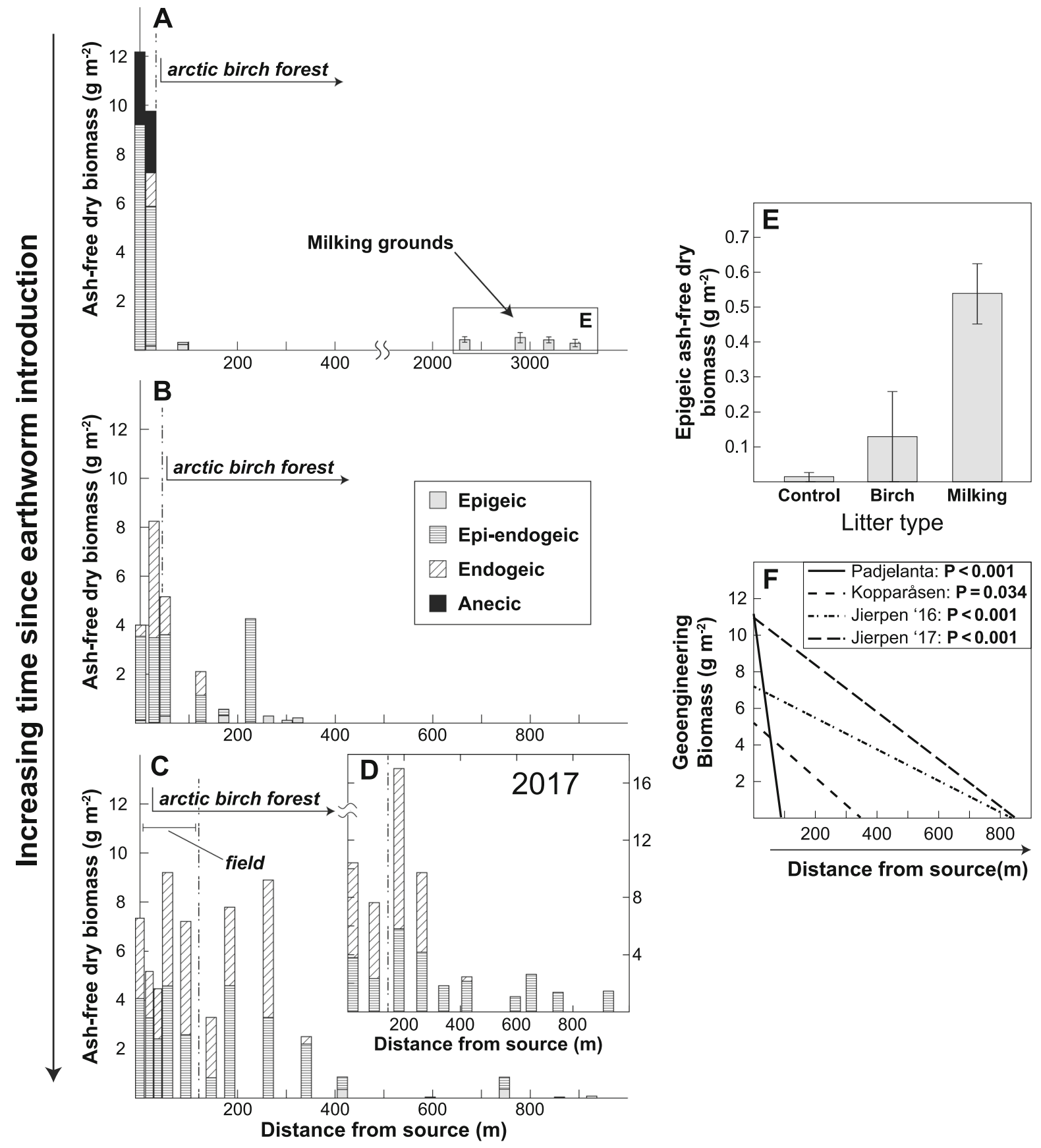

(epi-endogeic) and various endogeic Aporrectodea sp. including Aporrectodea calignosa complex, Aporrectodea rosea, and Aporrectodea trapezoides. At Jierpen, the control gradient showed none of these species as long as the two gradients were separated by a stream, further stressing that dispersal from the farmland is the main explanation for the observed spatial trends. Similarly diverse communities were identified in a modern compost from the Sami village of Staloluokta in the heart of Padjelanta national park. Local Sami residents informed us that earthworms were absent until their introduction by fishermen at the end of the 1970s (Sven-Ingvar Blind, personal comm.), further supporting our interpretation of a 
4Fig. 3 Total earthworm biomass (converted to ash free biomass, see methods) broken down by functional type plotted versus distance from source (abandoned farm or compost) at the three detailed arctic gradients in a Staloluokta, Padjelanta, b Kopparåsen, c Jierpen 2016 and d Jierpen 2017. Biomass values shown represent an average of within site replicates $(n=1$ 3 ). The border between the anthropogenic source area and surrounding birch forest is indicated with a dashed line. Note that all Lumbricus juveniles are classified as epi-endogeic given the absence of anecic Lumbricus terrestris adults at the Kopparåsen and Jierpen sites. Lumbricus juveniles were also classified as epi-endogeic in the Padjelanta gradient for consistency. e Epigeic (D. octaedra) biomass with vegetation type in Padjelanta national park. Dendrobaena biomasses are significantly higher $(P<0.05)$ within the old Sami milking grounds $(\mathrm{N}=4)$ than in the control plots $(\mathrm{N}=4)$. Note that no geoengineering species were observed here and thus, $y$-axis units are different than in (a-d). The milking ground biomasses are also shown as an inset in panel (a) for comparison. f Regression lines between distance from the anthropogenic sources and total biomass of geoengineering earthworms at Staloluokta $\left(\mathrm{F}_{1,7}=48.922, \mathrm{r}^{2}=0.87, \mathrm{P}<0.001\right)$, Kopparåsen $\left(F_{1,9}=6.213, \mathrm{r}^{2}=0.41, \mathrm{P}=0.034\right)$, Jierpen $2016\left(\mathrm{~F}_{1,24}=34.946\right.$, $\left.\mathrm{r}^{2}=0.59, \mathrm{P}<0.001\right)$ and Jierpen $2017\left(\mathrm{~F}_{1,31}=26.106\right.$, $\left.\mathrm{r}^{2}=0.46, \mathrm{P}<0.001\right)$ supporting hypothesis 3 . Note that the milking grounds were not included in the calculation of biomass versus distance for the Padjelanta gradient, since the milking grounds did not include geoengineering earthworms

non-native origin. Interestingly, Lumbricus terrestris, which is thought to have more strict environmental constraints with respect to climate and soil quality, was found in low densities within the compost at Staloluokta, making this one of the few reported occurrences of this species above the Arctic Circle in Fennoscandia (Terhivuo 1988; Nieminen et al. 2011). The between-site difference in the length of the geoengineering earthworm migration front seems to largely reflect differences in anthropogenic introduction, i.e. late 1970 s in Padjelanta, ca 1900 s at Kopparåsen (timing of railroad construction from Kiruna, Sweden to Narvik, Norway), and ca 1850s at Jierpen when agriculture first arrived to the interior of northern Sweden (Andersson et al. 2005). We also note that the estimated dispersal rates at these sites, inferred using our estimated arrival times, are directly comparable to North American analogues were migration rates have been estimated to be on the order of $\sim 5 \mathrm{~m}$ per year (e.g. Hale et al. 2005). The importance of man-made biotopes as the primary sources of geoengineering earthworms was further supported by our more general survey indicating multiple lawns, gardens and abandoned farms as
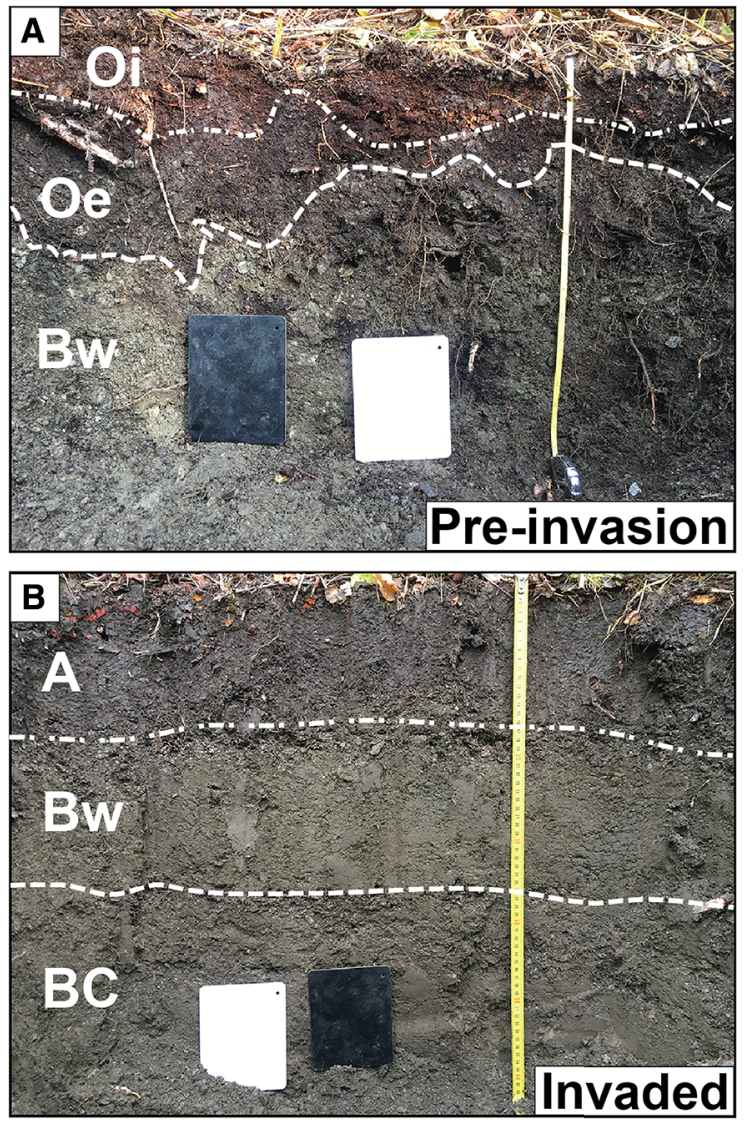

Fig. 4 a Soil pit $(51 \mathrm{~cm}$ depth) from the Jierpen gradient (Fig. 3c-d) showing genetic soil horizons in sub-alpine arctic birch forests developing in the absence of geoengineering earthworms. b Soil pit $(63 \mathrm{~cm})$ from Jierpen showing soil horizons in sub-alpine arctic birch forests following decades of geoengineering by non-native earthworms. Letters indicate genetic soil horizons. Black and white color cards are shown to illustrate color differences between photos. Note that the organic surface horizons (Oi and $\mathrm{Oe}$ ) have been completely mixed into the mineral subsoil, resulting in a thick $(\sim 20 \mathrm{~cm}) \mathrm{A}$ horizon in heavily invaded arctic forests

sources of geoengineering earthworm species across the Scandes (Table 2).

Our exploratory surveys stress that Lumbricus and Aporrectodea sp. are likely earthworm species that should be treated as non-native and invasive in the Fennoscandian arctic biome. In contrast to some other arctic countries where European earthworms are considered invasive (i.e. USA and Canada), the Nordic countries have no strategy regarding the dispersal of these earthworm species to sensitive environments. We call for immediate attention to the potential invasiveness of this species assemblage and list four 
Table $1 \mathrm{pH}$ values of humus and mineral soil for Fennoscandian boreal (Bothnian coastlines) and arctic environments surveyed for earthworms in this study

\begin{tabular}{|c|c|c|c|}
\hline Site type & Vegetation type & Sample matrix & Sample $\mathrm{pH}^{\mathrm{a}}$ \\
\hline (Invasion status) & (Distance from source) & (n) & $\left(\mathrm{H}_{2} \mathrm{O}, \mathrm{CaCl}_{2}\right)^{\mathrm{b}}$ \\
\hline \multicolumn{4}{|l|}{ Bothnian coastlines } \\
\hline \multirow[t]{3}{*}{ Successional gradients } & Spruce_Picea abies & Humus $(\mathrm{n}=14)^{\mathrm{c}}$ & $(3.9,3.3)$ \\
\hline & Alder-Alnus incana & Humus $(\mathrm{n}=17)$ & $(5.0,4.5)$ \\
\hline & Driftwood (thick litter) & Litter/Humus $(\mathrm{n}=9)$ & $(5.8,5.5)$ \\
\hline \multicolumn{4}{|l|}{ Padjelanta national park } \\
\hline Sami cultural soils & Milking ground & Humus & $(4.3)^{\mathrm{d}}$ \\
\hline Controls & Vaccinium tundra & Humus & $(3.8)^{\mathrm{d}}$ \\
\hline \multicolumn{4}{|c|}{ Arctic invasion gradients (near Abisko) } \\
\hline Jierpen & Birch forest & Humus $(\mathrm{n}=20)^{\mathrm{e}}$ & $(5.2,4.6)$ \\
\hline (Pre-invasion) & (>341 m from source) & Mineral soil $(n=18)^{f}$ & $(5.5,4.7)$ \\
\hline Jierpen & Field/Birch forest & Humus $(n=4)$ & $(5.1,4.8)$ \\
\hline 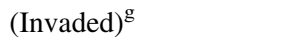 & $(<341 \mathrm{~m}$ from source $)$ & Mineral soil $(\mathrm{n}=20)$ & $(6.4,5.5)$ \\
\hline Kopparåsen & Birch forest & Humus $(\mathrm{n}=8)$ & $(4.8,4.4)$ \\
\hline (Pre-invasion) & $(>171 \mathrm{~m}$ from source) & Mineral soil $(n=6)$ & $(5.4,4.1)$ \\
\hline Kopparåsen & Field/Birch forest & Humus $(\mathrm{n}=2)$ & $(5.2,4.9)$ \\
\hline (Invaded) & $(<171 \mathrm{~m}$ from source) & Mineral soil $(\mathrm{n}=8)$ & $(5.6,5.1)$ \\
\hline
\end{tabular}

${ }^{a}$ Standard error $(\sigma)$ for all sites and matrix types was in the range of $\pm 0.1-0.4$

${ }^{\mathrm{b}} \mathrm{pH}$ was measured in $0.02 \mathrm{M} \mathrm{CaCl}_{2}$ following $\mathrm{pH}$ determination in water

${ }^{c}$ Humus was sampled in bulk to $20 \mathrm{~cm}$ depth. When humus thickness $<20 \mathrm{~cm}$, the entire depth profile was collected

${ }^{\mathrm{d}} \mathrm{pH}$ values for Padjelanta cultural soils and adjacent control plots were collected during a study by Egelkraut (2017) by extracting $2 \mathrm{~g}$ fresh soil in $50 \mathrm{ml} 1 \mathrm{M} \mathrm{KCl}$ solution. Samples were shaken for 2 hours and left to settle overnight before measuring $\mathrm{pH}$

${ }^{\mathrm{e}}$ At the arctic gradients, humus was sampled to $10 \mathrm{~cm}$ depth (when present). If humus thickness $<10 \mathrm{~cm}$, the entire depth profile was collected

${ }^{\mathrm{f}}$ The upper $10 \mathrm{~cm}$ of the mineral soil profile was collected, either beginning at the base of the humus layer (when present) or at the ground surface in the absence of an organic horizon

${ }^{\mathrm{g}}$ We defined (Invaded) as the stage along our invasion gradients where the forest floor displays a (relatively) continuous humus layer. Fields and birch forests with diverse, well-established geoengineering earthworm communities are typically devoid of an organic horizon

main reasons for our concern. First, the observed geoengineering earthworm species are known to be drivers of dramatic environmental changes in other formerly glaciated environments, including negative effects on native plants and preferential selection for non-native plants and graminoids (Roth et al. 2015; Craven et al. 2016), increased greenhouse gas emissions (Lubbers et al. 2013) and depletion of key nutrients in surface soils (Resner et al. 2015). We also note that the earthworm-driven modifications to soil morphologies appears to largely resemble observations from North American forests (Fig. 4a, b), wherein thick organic soil horizons (O horizon) diminish after the establishment of geoengineering earthworms while the underlying organic rich mineral soil (A horizon) expands (Lyttle et al. 2015). Second, measured earthworm biomasses in Fennoscandian arctic birch forests adjacent to anthropogenic source areas are comparable to biomasses in North American temperate and boreal forests where invasive earthworms are recognized as a potent threat (e.g. Hale et al. 2006; Eisenhauer et al. 2007; Resner et al. 2015). 
Table 2 Results from the site selective surveys of earthworm communities in proximity to anthropogenic sources across the Fennoscandian arctic alpine region (i.e. the Scandes)

\begin{tabular}{|c|c|c|c|c|c|}
\hline \multirow[t]{2}{*}{ Site name } & \multicolumn{2}{|c|}{ Native epigeic (litter) species } & \multicolumn{3}{|c|}{ Geoengineering species } \\
\hline & Dendrobeana octaedra & Dendrodrilus rubidus & Aporrectodea sp. & Lumbricus rubellus & Lumbricus terrestris \\
\hline Jierpen & $\mathrm{B}$ & $\mathrm{B}$ & $\mathbf{B}, \mathrm{F}$ & $\mathbf{B}, \mathrm{F}$ & \\
\hline Kopparåsen & $\mathrm{B}$ & $\mathrm{B}$ & $\mathbf{B}, \mathrm{F}$ & $\mathbf{B}, \mathrm{F}$ & \\
\hline Staloluokta & $\mathrm{B}, \mathrm{C}, \mathrm{L}$ & $\mathrm{B}, \mathrm{L}$ & $\mathrm{L}$ & $\mathbf{B}, \mathrm{C}, \mathrm{L}$ & $\mathrm{C}, \mathrm{L}$ \\
\hline Milking ground & $\mathrm{A}, \mathrm{F}$ & & & & \\
\hline Abiskojaure & A & & & & \\
\hline \multicolumn{6}{|l|}{ Alesjaure } \\
\hline \multicolumn{6}{|l|}{ Sälkastugorna } \\
\hline \multicolumn{6}{|l|}{ Singistugorna } \\
\hline Teusajaure & $\mathrm{B}, \mathrm{L}$ & & $\mathbf{B}, \mathrm{L}$ & $\mathbf{B}, \mathrm{L}$ & \\
\hline Vakkotavare & $\mathrm{B}$ & $\mathrm{B}, \mathrm{L}$ & $\mathrm{L}$ & B, L & \\
\hline Vissijaure & $\mathrm{G}, \mathrm{L}$ & $\mathrm{L}$ & & $\mathrm{G}, \mathrm{L}$ & \\
\hline Stordalen & $\mathrm{L}$ & & & $\mathrm{L}$ & \\
\hline Kaisepakte & $\mathrm{B}, \mathrm{F}, \mathrm{L}$ & & $\mathbf{B}, \mathrm{L}$ & B, F, L & \\
\hline Stenbacken & & & $\mathbf{B}, \mathrm{L}$ & B, L & \\
\hline Torneträsk & $\mathrm{G}, \mathrm{L}$ & & $\mathrm{G}, \mathrm{L}$ & $\mathrm{G}, \mathrm{L}$ & \\
\hline Abisko village & $\mathrm{B}, \mathrm{G}, \mathrm{L}$ & $\mathrm{C}, \mathrm{L}$ & & $\mathbf{B}, \mathrm{G}^{\mathrm{a}}, \mathrm{L}$ & \\
\hline
\end{tabular}

Distributions of earthworm species argued to be native (Dendrobeana octaedra and D. rubidus) as well as those that are non-native and invasive in the arctic biome (Aporrectodea sp., L. rubellus and L. terrestris) are shown with respect to the environments in which they occur across the region. Letters indicate source areas and adjacent environments where specific earthworm species were identified (or were absent) at all survey locations shown in Fig. 1. These include acidic tundra (A), sub-alpine arctic birch forests (B), modern composts (C), abandoned fields (F), modern gardens or greenhouses (G), and modern lawns (L). Locations where geoengineering earthworms have migrated beyond the boundary of man-made biotopes and thus occur in the alpine birch forest stands adjacent to their source areas are highlighted in bold. Empty row indicate absence of species

Lumbricus juveniles cannot be distinguished between rubellus and terrestris

$A$ acidic tundra; $\boldsymbol{B}$ arctic alpine birch forest; $C$ modern compost; $F$ abandoned farm field; $G$ modern garden; $L$ modern lawn

${ }^{a}$ Includes greenhouses and gardens used by researchers at the Abisko Scientific Research Station

Third, we know from previous studies that earthworms are almost impossible to eradicate once they have invaded a system. Finally, the limited historical impact from humans on the Fennoscandian alpine environment makes this area one of the few remaining northern European biomes where anthropogenic spreading of earthworms is likely still limited. Thus, there is an urgent need for further assessment of this on-going earthworm invasion that can aid decisionmaking as to whether measures should be taken to restrict the spread of geoengineering earthworm species to the Fennoscandian arctic, before they have become fully established.

Acknowledgements This project was funded by CFANS faculty development support, an Institute on the Environment mini-grant, and an Institute for Advanced Study residential fellowship to Yoo and a Wallenberg Academy Fellow grant to
Klaminder, as well as travel funding through a departmental fellowship to Wackett. We thank Thomas Westin and Matthias Olsen for valuable information on site history for the Jierpen and Padjelanta gradients, respectively.

Open Access This article is distributed under the terms of the Creative Commons Attribution 4.0 International License (http:// creativecommons.org/licenses/by/4.0/), which permits unrestricted use, distribution, and reproduction in any medium, provided you give appropriate credit to the original author(s) and the source, provide a link to the Creative Commons license, and indicate if changes were made.

\section{References}

Alban DH, Berry EC (1994) Effects of earthworm invasion on morphology, carbon, and nitrogen of a forest soil. Appl Soil Ecol 1:243-249 
Andersson R, Ostlund L, Tornlund E (2005) The last European landscape to be colonized: a case study of land-use change in the far north of Sweden 1850-1930. Environ Hist 11:293-318

Cameron EK, Bayne EM, Clapperton MJ (2007) Human-facilitated invasion of exotic earthworms into northern boreal forests. Ecoscience 14:482-490

Costello DM, Tiegs SD, Lamberti GA (2011) Do non-native earthworms in Southeast Alaska use streams as invasional corridors in watersheds harvested for timber? Biol Invasions 13:177-187

Craven D, Thakur MP, Cameron EK et al (2016) The unseen invaders: introduced earthworms as drivers of change in plant communities in North American forests (a metaanalysis). Glob Change Biol 23:1065-1074

Egelkraut D (2017) Long-lasting ecological legacies of reindeer on tundra vegetation. Umeå University, Umeå, $33 \mathrm{pp}$

Eisenhauer N, Partsch S, Parkinson D, Scheu S (2007) Invasion of a deciduous forest by earthworms: changes in soil chemistry, microflora, microarthropods and vegetation. Soil Biol Biochem 39:1099-1110

Gates GE (1982) Farewell to North American megadriles. Megadrilogica 4:12-77

Gundale MJ, Jolly WM, Deluca TH (2005) Susceptibility of a northern hardwood forest to exotic earthworm invasion. Conserv Biol 19:1075-1083

Gunn A (1992) The use of mustard to estimate earthworm populations. Pedobiologia 36:65-67

Hæggström CA, Terhivuo J (1979) The Lumbricidae (Oligochaeta) in the archipelago of Åland, SW Finland. Memoranda Soc Fauna Flora Fennica 55:17-31

Hale CM, Reich PB, Frelich LE (2004) Allometric equations for estimation of ash-free dry mass from length measurements for selected European earthworm species (Lumbricidae) in the western Great Lakes region. Am Midl Nat 151:179-185

Hale CM, Frelich LE, Reich PB, Pastor J (2005) Effects of European earthworm invasion on soil characteristics in northern hardwood forests of Minnesota, USA. Ecosystems 8:911-927

Hale CM, Frelich LE, Reich PB (2006) Changes in hardwood forest understory plant communities in response to European earthworm invasions. Ecology 87:1637-1649

Hendrix PF, Callaham MA Jr, Drake JM, Huang C, James SW, Snyder BA, Zhang W (2008) Pandora's box contained bait: the global problem of introduced earthworms. Annu Rev Ecol Evol Syst 39:593-613

Jaenike J, Selander RK (1979) Evolution and ecology of parthenogenesis in earthworms. Am Zool 19:729-737

Lubbers IM, van Groenigen KJ, Fonte SJ, Six J, Brussaard L, van Groenigen JW (2013) Greenhouse-gas emissions from soils increased by earthworms. Nat Clim Change 3:187-194

Lyttle A, Yoo K, Hale CM, Aufdenkampe A, Sebestyen SD, Resner K, Blum A (2015) Impact of exotic earthworms on organic carbon sorption on mineral surfaces and soil carbon inventories in a northern hardwood forest. Ecosystems 18:16-29

Muldal S (1952) The chromosomes of the earthworms I. The evolution of polyploidy. Heredity 6:55-76

Nieminen M, Ketoja E, Mikola J, Terhivuo J, Sirén T, Nuutinen V (2011) Local land use effects and regional environmental limits on earthworm communities in Finnish arable landscapes. Ecol Appl 21:3162-3177

Pleasant JM (2011) The paradox of plows and productivity: an agronomic comparison of cereal grain production under iroquois hoe culture and European plow culture in the seventeenth and eighteenth centuries. Agric Hist 85: 460-492

Resner K, Yoo K, Sebestyen S, Aufdenkampe A, Hale CM, Lyttle A, Blum A (2015) Invasive earthworms deplete key soil inorganic nutrients $(\mathrm{Ca}, \mathrm{Mg}, \mathrm{K}$, and $\mathrm{P})$ in a northern hardwood forest. Ecosystems 18:89-102

Roth AM, Whitfeld TJS, Lodge AG, Eisenhauer N, Frelich LE, Reich PB (2015) Invasive earthworms interact with abiotic conditions to influence the invasion of common buckthorn (Rhamnus cathartica). Oecologia 178:219-230

Skoglund P, Malmström H, Raghavan M, Storå J, Hall P, Willerslev EM, Gilbert TP, Götherström A, Jakobsson M (2012) Origins and genetic legacy of neolithic farmers and hunter-gatherers in Europe. Science 336:466-469

Svensson JS, Jeglum JK (2003) Spatio-temporal properties of tree-species belts during primary succession on rising Gulf of Bothnia coastlines. Ann Bot Fennici 40:265-282

Terhivuo J (1988) The Finnish Lumbricidae (Oligochaeta) fauna and its formation. Ann Zool Fennici 25:229-247

Terhivuo J, Saura A (2006) Dispersal and clonal diversity of North-European parthenogenetic earthworms. Biol Invasions 8:1205-1218 